\title{
Enquiry Based Learning: A Valuable Mechanism at Level 9?
}

\section{Wright, Angela}

Department of OPD, School of Business, CIT, Cork, Ireland.

\begin{abstract}
This paper examines 'Enquiry Based Learning' (EBL) as an engagement strategy for assessment at 'taught masters' level 9. The master students in question are adult learners in full time employment and the empirical data was gathered from these students. First, an outline of the key features of EBL is presented and, from there, an investigation of how it is viewed when applied to a specific problem statement by the masters students. EBL creates a memorable atmosphere in the classroom and encourages deep learning (Ramsden, 1992). EBL also encourages active learning, which is more enjoyable for the students (Eison, 2010), especially adults - offering more control (Whowell, 2006). Learning should not be passive or a spectator sport; students learn most effectively by active engagement (Karmas, 2006), with an interesting project, hence, the use of EBL. It is vital that we move beyond a conceptualisation of education as the simple acquisition of knowledge to one which equally emphasises, nurtures and assesses innovation and expertise in the utilisation and application of knowledge, (Boland, 2010). The findings of this research are relevant and important as they inform practice and feed into future programme reviews when considering the inclusion of EBL for assessment.
\end{abstract}

Keywords: Enquiry Based Learning (EBL), Assessment, Engagement, Adult Learners. 


\section{Introduction}

The engagement of Higher Education (HE) institutions with the wider community and engagement with the world outside of the institution setting has become part of the language of HE, (Hunt, 2011; Wynne, 2014). Engagement is an 'umbrella term' that covers a very wide range of strategies \& activities (Wynne, 2014), but, in the context of this discussion on EBL, it leads to the encouraged use of working with 'real life' issues and problems outside of the educational institution for pedagogical enhancement. Attempts at engagement present challenges on two fronts: in the day-to-day order of how a university conducts its work, and in higher order considerations around values, identity and purpose (Wynne, 2014). Emphasis is placed on public scholarship, on sharing the expertise of the university more broadly, and on learning from communities, to contribute to public problem solving, where civically engaged universities are mindful of the contribution they make to the economy, (Wynne, 2014). Hutchings (2007) attempts to set out the philosophical bases of EBL, and argues that the true sources of EBL are to be found in enlightenment thought, its epistemology and in its aesthetics.

\section{Research Context}

The purpose of this research is to examine the use of EBL as an appropriate assessment tool for the adult learner at masters level. Adult learners are defined either based on their age, cognitive maturity, or, as a non-traditional learner (Yap, 2009). The adult learner brings a differnet perspective to the classroom and varying standpoints to education, in terms of emotion, motivation, and financial resource, when compared to students entering higher education through normal channels after second level education. Students learn differently in varying situations (Ramsden, 1992), and this is to the fore with adult learners. Connotation varies greatly with each student but especially with the adult learner (Ramsden, 1992). Considered reflection is therefore important when developing and applying appropriate assessment strategies for adult learners. EBL has been used for a number of years as an assessment strategy and, now, some informed student feedback is timely. 


\section{Literature}

Solving problems in HE was developed initially for Medical education, (Ertmer \& Simons, 2006), and different perspectives exist on its role in HE. Miles (2006) believes that the use of EBL in HE prepares students to be more effective in the real world situations in which they work, and to return to their places of work with the skills and knowledge that they need to develop policy \& implement change. Advocates of EBL can outline numerous benefits of EBL such as teamwork, critical thinking, problem solving, deep learning etc., but are reluctant to acknowledge any disadvantages, such as the ability of students to gain and develop large knowledge about the particular topic, the difficulties for instructors and, in general, the need to change the ethos of the educational institution. Gaining large quantities of knowledge in a fast manner is typically suited to a traditional classroom situation and not problem solving. Problem solving is still not yet widely used (Ertmer \& Simons, 2006). Implementation and operational issues around EBL \& PBL are challenging and much more taxing for the instructor. Instructors need to have a much boarder skill set, and be able to adapt and be flexible (Ertmer \& Simons, 2006) to this changing learning environment when compared to traditional classrooms - the instructor is now facilitating and not instructing, and also a provider of scaffolds ${ }^{1}$ (Resier, 2004) for the student. Transitioning to this type of guidance is exigent. Barrett (2005) considers problem solving not merely as a teaching \& learning technique, but a total approach to education and outlines several philosophical principles underpinning Problem-based Learning; [(Lewin, 1943; Freire, 1972; 1985; Margeston, 1997)-in Barrett (2005)].

\subsection{What is Enquiry Based Learning (EBL)?}

Problem and Enquiry-based Learning are multifaceted in nature, and are not mere teaching techniques but rather total educational strategies (Barrett, 2005). According to Kahn \& O'Rourke (2005), EBL describes approaches to learning that are driven by a process of enquiry. The tutor establishes the task and supports/facilitates the process, but the students pursue their own lines of enquiry, draw on their existing knowledge and identify the consequent learning needs. They seek evidence to support their ideas and take responsibility for analysing and presenting this appropriately, either as part of a group, or, as an individual supported by others. They are thus engaged as partners in the learning process (Kahn \& O'Rourke, 2005), and students can actually take control of their learning (Whowell, 2006). EBL, however, while incorporating elements of PBL, also covers a broader spectrum of approaches (Kahn \& O’Rourke).

\footnotetext{
1 A teacher assists a learner, altering the learning task, so that the learner can solve problems or accomplish tasks that would otherwise be out of reach, (Resier, 2004:274).
} 


\subsection{EBL V PBL}

Much of the literature uses the terms EBL and PBL interchangeably - although some theorists suggest differences. Kahn \& O'Rourke (2005) outline for example, that EBL has a definite overlap with Problem-based Learning (PBL), where the handling of a problem defines and drives the whole learning experience of the students. EBL, however, is more far reaching in nature (Kahn \& O'Rourke, 2005). Problem Based Learning originated from innovative health sciences and progressed into mainframe schools and Universities. PBL is a learner-centered approach - students engage with the problem (Savery, 2006). Problembased Learning is seen as a set of approaches under the broader category of Enquiry-based Learning and is a total approach to education (Barrett, 2005). Within PBL, significant time is involved in the search for relevant resources. If a sufficient set of relevant resources has already been collated, then the time for searching will be reduced (Kahn \& O'Rourke, 2005). In PBL, the students define their own learning issues (Barrett, 2005). Interestingly, one of the main defining characteristics of Problem-based Learning, which distinguishes it from some other forms of Enquiry-based Learning, is that the problem is presented to the students first at the start of the learning process, before other curriculum inputs (Barrett, 2005). This is an important point to note.

By contrast, EBL advocates a wider use of project work or research activity, emphasising the use of project-work to master a given body of knowledge itself, and not simply to make connections within an existing body of knowledge. This approach is a key factor that distinguishes an enquiry-based approach from a more traditional use of projects. During the EBL process, students are facilitated to construct their knowledge (in Kahn \& O'Rourke). Certainly, EBL facilitates deep, and especially, memorable learning (Whowell, 2005), and is now implemented in higher education institutions across the U.K. and worldwide in a wide and diverse list of subject areas (Whowell, 2006).

\section{Methodology}

The main objective of this research is to inform practice, and examine the value of EBL with more appropriate informed thinking at masters level. For the purposes of this research study, it was considered appropriate to apply a positivistic research methodology. A quantitative research survey instrument using Likert questions was devised based on surveys and suggestions on educational research on Survey Monkey. Quantitative measurements and hard facts may be of more use in demonstrating concrete achievement to the researcher (Harvey, 1998). The survey was completely confidential as it was deemed that it was necessary to make contributions confidential and anonymous to access negative feedback (Harvey, 1998). This allowed graduates the freedom and confidence to make a relevant and genuine contribution to the research. Sixty two graduates (male \& female 23- 
55 years of age), consisting of the total population for the last three years of the taught masters programme, were invited to give feedback on this method of assessment. This was considered an appropriate sample size; more students could have been invited to participate, but it was believed that a more recent pool was more beneficial. Prior to sending out the survey, the questionnaire was tested to eliminate any errors and cleansed prior to surveying the sample proper. When the survey was ready, an email was sent to the sixty two graduates with the survey link attached with a request to complete same in the interest of improving practice. Four of the emails bounced (the emails on file were work emails), implying that the graduates had moved from their work and relevant email to another position. Therefore, the working sample was reduced to 58. The response rate was good with 40 graduates of the relevant 58 taking the survey - a response rate of $68.96-70 \%$.

\section{Findings}

On the masters programme, the use of EBL is encouraged and considered the best approach for assessment at group level within HE. The key reason for using EBL and not PBL is due to the fact that the 'Enquiry' assignment is not presented to the students until week 4 of the term, (in line with Barrett), as it is necessary to present relevant theory to the groups in advance of their 'Enquiry' process so that they are fully informed. For the initial lecture, the format \& process of what will happen throughout the module is provided to the students (Hadgraft, 2000). Findings from this research, however, reveal that graduates would actually like to get the problem earlier in the term due to its short nature (12 weeks) prior to week 4.

For the EBL, an organisation is chosen by the lecturer (who will facilitate the learning), and the research problem is developed in conjunction with the organisation. Overall, and in line with the literature, respondents were satisfied with the quality of the organisations, and derived particular satisfaction when it involved a 'not for profit' organisation (86\%) especially. Problems that are current, local, relevant, \& authentic were welcomed by respondents as they are viewed as beneficial to both parties to the exercise. "The best elements of the course were the live case studies and the guest speakers". "The speakers from industry worked very well and gave excellent insights into their companies and problems".

This research findings found that EBL as a method of assessment was both engaging and challenging for students. $89 \%$ stated that EBL was challenging, but in a "positive way", with only $7 \%$ stating that it was "stressful". When asked about working together in groups to 'problem solve'; $38 \%$ stated that problem solving in groups "helped me to work better in a team setting" and ultimately, in a work setting. $38 \%$ stated that it improved their professional development skills, and $25 \%$ stated that it improved their communication skills. 
In line with the literature, when setting the EBL problem, it was important that a clear language \& unambiguous terminology is used to define concrete concepts \& goals, \& acknowledge \& reward successful outcomes (Wynne, 2014). Sophisticated problem solving requires strategies for planning and guidance with good quality scaffolds (Resier, 2004). The EBL "forced us to structure our learning and to plan well".

By contrast, some respondents were concerned with 'free loading", where weaker students gained an advantage by using EBL. "By nature, group work tends to allow weaker team members to coast on the coat tails of others, so, perhaps, a certain structure within the group work scenario could be established to address this". It could be easy for some students to be 'carried along' particularly in larger project groups". On balance however, students engaged well with the EBL. "I loved working with actual companies and believe that these types of projects benefitted me most". Overall, the participants were satisfied with the assessment strategy applied for the EBL; (presentation to the relevant company and feedback from same), with $86 \%$ stating this. However, concern was still expressed in terms of 'free loading' of students.

\section{Discussion \& Conclusion}

Tell me and I forget, show me and I remember, involve me and I understand, (SpronkenSmith).

Biggs (1999a) believes that setting a problem and encouraging enquiry is a perfect way to assess students and it also complies with alignment. The findings of this research support that concept. Some graduates expressed a concern around the 'free loading' of others while working on the EBL; however, a solution to this can be found by offering a range of assessment methods, matching the complex open-ended nature of an enquiry (Biggs, 1999b). Macdonald (2005) notes that the real challenge is to make assessment rewarding, challenging, and a fun learning experience! This is mirrored in the research findings.

This research recommends the application of a Tripartite Assessment (Macdonald \& SavinBaden, 2004), while using EBL at masters level. Firstly, the group submits a report for which they receive a mark. Secondly, the individual submits the piece of work they researched. Finally, the individual writes an account of the group process that is linked to the theory of group work. These three components are added together to form the overall individual mark (Macdonald \& Savin-Baden, 2004). The advantage of this is that it does not privilege some students who do less work, and an individual student will be responsible for gaining two-thirds of the marks and therefore most students perceive this kind of grading as being fair (Macdonald, 2005). This solution will address the 'free loading' concerns expressed in this research. 
Participants also expressed the view that they are anxious to start the EBL as soon as possible in the term before week 4, for example. This may need to be addressed given the short term time of 12 weeks. If this is to be considered for the future of the masters, then the EBL as defined by Barrett (2005) may well have to become a PBL where the problem can be presented prior to academic delivery. Theorists provide much debate around the ideas \& philosophies for the use of EBL \& PBL, with advocates providing compelling benefits in the literature. The use of any type of problem solving certainly provides new challenges for instructor \& student alike, but, on balance, the case for its use in a blended format is compelling. EBL certainly presents the benefits along with disadvantages for student \& lecturer alike, but, holistically, the advantages have a clear recompense, as the students will reap the rewards of being able to undertake EBL as if part of a 'real life' team in an organizational setting, as outlined by one student, "projects where you work with real companies are supremely productive \& invigorating!’”.

\section{References}

Barrett, T. (2005). "Understanding Problem Based Learning", Handbook of Enquiry and

Problem-based Learning: Irish Case Studies and International Perspectives, No 2., (eds), Terry Barrett, Iain Mac Labhrainn \& Helen Fallon, Galway, Centre for Excellence in Learning and Teaching, AISHE Readings, pp 13-25.

Biggs, J. (1999a). "What the student does: teaching for enhanced learning",

Higher Education Research and Development, Vol. 18, No. Baccessed, April 112016 at $9 \mathrm{pm}$.

Biggs, J. (1999b). Teaching for Quality Learning at University. Buckingham: SRHE/Open

University Press.

Boland, T. (2010). "Joint Oireachtas Committee on Education and Skills Meeting on

Curriculum Issues", available at www.oireachtas.ie/documents/...jeducationscience/.../20101213-12.doc, accessed May 112016 at 2pm.

Eison, J. (2010). "Using Active Learning Instructional Strategies to Create Excitement and Enhance Learning", available at, http://www.cte.cornell.edu/documents/presentations/Active\%20Learning\%20$\% 20$ Creating $\% 20$ Excitement $\% 20$ in $\% 20$ the $\% 20$ Classroom $\% 20-\% 20$ Handout.pdf, accessed, April 22016 at 9pm.

Ertmer, P. A. \& Simons, K. D. (2006). "Jumping the PBL Implementation Hurdle: Supporting the Efforts of K-12 Teachers". Interdisciplinary Journal of Problem-based Learning, 1(1). 
Hadgraft, R. (2000). "A Personal Journey Towards A Problem-based Approach to University Teaching Case Studies", The Flexible Learning Guide, Number 2, Australia: Centre for Higher Education Development.

Harvey, J. (1998). "Selecting your student sample", in Evaluation Cookbook, ed., Jen Harvey, Scottish Higher Education Funding Council, Edinburg: The Learning Technology Dissemination Initiative.

Hunt, C. (2011). "National Strategy for Higher Education to 2030; Report of the Strategy Group", The Hunt Report, Dublin: Department of Education and Skills.

Hutchings, B. (2007). "The philosophical bases of Enquiry-Based Learning", Centre for Excellence in Enquiry-Based Learning Essays and Studies, Manchester: University of Manchester.

Kahn P., \& O’Rourke, K. (2005). “Understanding Enquiry-Based Learning”, Handbook of

Enquiry and Problem-based Learning: Irish Case Studies and International Perspectives, No 2., (eds), Terry Barrett, Iain Mac Labhrainn \& Helen Fallon, Galway, Centre for Excellence in Learning and Teaching, AISHE Readings.

Karmas, C. (2006). "Active Learning in the Humanities Classroom, Everything, Nothing, Something, Anything", The international Journal of the Humanities, Active Learning in the Humanities Classroom, Vol 3. No 6.

Macdonald, R. (2005). “Assessment strategies for enquiry and problem-based learning”,

Handbook of Enquiry and Problem-based Learning: Irish Case Studies and International Perspectives, No 2., (eds), Terry Barrett , Iain Mac Labhrainn \& Helen Fallon, Galway, Centre for Excellence in Learning and Teaching, AISHE Readings.

Macdonald R., \&Savin-Baden, M. (2004). “ Briefing on Assessment on Problem-BasedLearning”, Assessment Series No 13., LTSN Generic Centre.

Miles, S. (2006). "Using inquiry based learning to study inclusive education: an evaluation of the 'School Based Inquiry and Development' course unit, MEd Special and Inclusive Education, 2005/6”, Manchester: University of Manchester.

Ramsden, P. (1992). Learning to Teach in Higher Education, NY:Routhledge Falmer.

Resier, B.J., (2004). "Scaffolding Complex Learning: The Mechanisms of Structuring and Problematizing Student Work", The Journal of the Learning Sciences, 13(3), 273-304.

Savery, J.R. (2006). “Overview of Problem-Based Learning: Definitions and Distinctions", Interdisciplinary Journal of Problem-Based Learning, Vol 1., No. 1.

Spronken-Smith, R. "Experiencing the Process of Knowledge Creation: The Nature and 
Use of Inquiry-Based Learning in Higher Education", University of Otago, New Zealand. , available at https://akoaotearoa.ac.nz/sites/default/files/u14/IBL\%20-\%20Report\%20\%20Appendix\%20A\%20-\%20Review.pdf, accessed May 112016 at $5 \mathrm{pm}$.

Whowell, M. (2006). A Student Guide to Enquiry-Based Learning, available at http://www.ceebl.manchester.ac.uk/resources/guides/studentguide_july06.pdf, accessed April 12, 2016 at 9pm.

Wynne, R. (2014). "Higher Education Civic Engagement: Project or Orientation”, AISHEJ, Vol.6., No.1, available at, http://ojs.aishe.org/index.php/aishe-j/article/view/147/231; Accessed, May 112016 at 12pm.Yap, Roger, Chao, R., JR. (2009). "Understanding the Adult Learners Motivation and

Barriers to Learning more", ESREA, 6-8 November, Greece: University of Macedonia Thessaloniki. 